\title{
CHEMICAL SPECIATION OF ARCHAEOLOGICAL OBJECTS BY XRF/XANES ANALYSIS USING SYNCHROTRON RADIATION
}

\author{
IZUMI NAKAI ISAMU TAGUCHI* and KAZUO YAMASAKI** \\ Dept. of Chemistry, University of Tsukuba, Ibaraki 305, Japan \\ * National Museum of Japanese History, Sakura, Chiba 285, Japan \\ ** Professor Emeritus, Nagoya University, Nagoya 464, Japan
}

\begin{abstract}
Synchrotron Radiation Induced X-ray Fluorescence analysis was successfully applied to the analysis of archaeological objects. The method enables us to carry out nondestructive microprobe analysis of the samples. This study shows that XANES spectrum obtained by the X-ray fluorescence detection is suitable for chemical state analysis of elements in a micro-region. The following two examples are shown to illustrate the advantage of the method: two dimensional analysis of clay doll made in China in A.D. $4 \mathrm{c}$ and chemical state analysis of iron in black glaze of the fragments of Temmoku bowl excavated at the kiln site in southern China.
\end{abstract}

Key words Synchrotron radiation, X-ray Fluorescence Analysis, Archaeology, Chemical state analysis, XANES

XRF technique has been widely used in the chemical analysis of ancient artifacts, because the method enable us to carry out a nondestructive rapid multielemental analysis of the samples. It is expected that application of SR X-ray to the XRF analysis will greatly improve its analytical ability because of the high brightness, polarization, and wavelength tunability of the SR X-ray.

Taking these advantages, we have started the following research projects in order to establish the experimental procedures of archaeometric analysis and to apply the technique to the practical problems in archaeology and art[1]:

1) Two dimensional chemical imaging of artistic pattern This technique is used for the transformation of artistic pattern into two dimensional chemical compositional image. This technique is particularly useful when the pattern is complicated or very small.

2) Multielemental nondestructive bulk analysis for provenance investigation Capability of rapid and non-destructive multielemental analysis allows to investigate a large number of samples, which are necessary for provenance investigation and documentation of ancient trade routes. Highly polarized and energy-tunable radiation allow to analyze a trace amount of desired element, which can be a fingerprint element for the above purposes.

3) Chemical speciation of component elements of archaeological objects by XANES Chemical speciation of elements in archaeological samples such as pottery is important in archaeometry because such information is useful to elucidate manufacturing techniques of the products. XANES (X-ray Absorption Near Edge Structure) analysis is suitable for this purpose because it allows nondestructive chemical state analysis of small region of a sample. We have applied the technique to the analysis of various archaeological samples: e.g., iron implements, glass and ceramic wares.

In this paper we report XRF imaging (Project 1) of a clay doll made in China in A.D. $4 \mathrm{c}$ and chemical state analysis (Project 3) of a fragment of Temmoku bowl excavated by Prof. J.M. Plumer in 1935 at the kiln site in southern China. There is a spot pattern, so called "oil spots", on the black glaze of the bowl. The origin of this pattern has been a problem of archaeology for long years[2].

\section{EXPERIMENTAL}

Measurements were made at BL-4A, Photon Factory, KEK using the energy dispersive XRF system with a $\mathrm{Si}(\mathrm{Li})$ detector. Schematic illustration of the measurement system is shown in Fig. 1. The sample was placed on a remote controlled X-Z stage perpendicular to the orbital plane of SR and excited by monochromated X-ray using Si(111) double crystals. A fine parallel beam of desirable size was obtained by a simple set of vertical and horizontal slits. Two dimensional intensity data were obtained by step scanning 


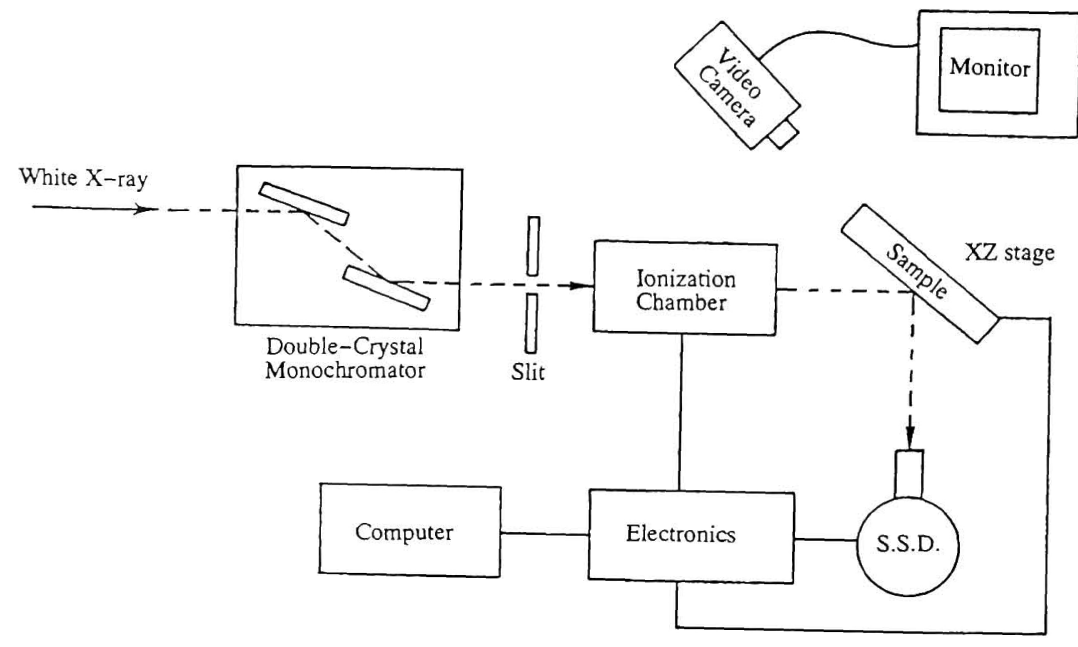

Fig. 1. Schematic illustration of the XRF measurement system at the Photon Factory

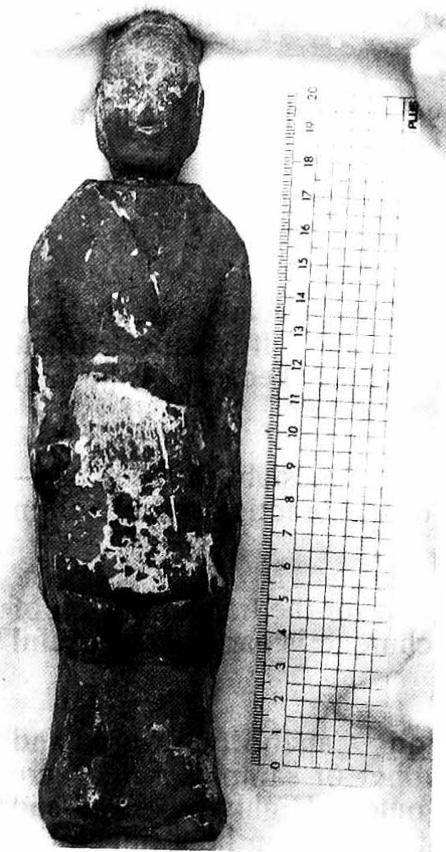

(a)

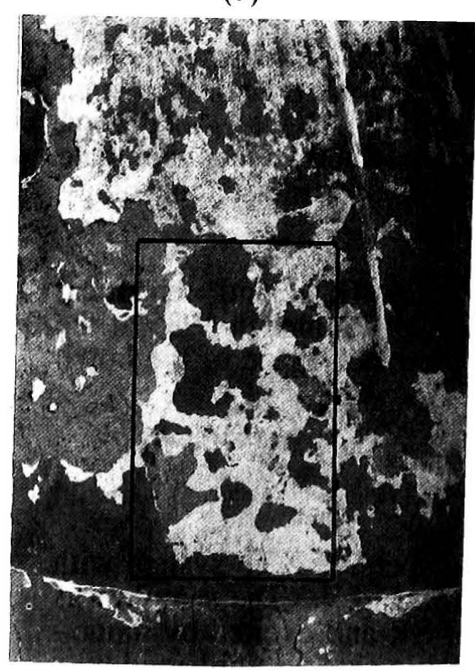

(b)

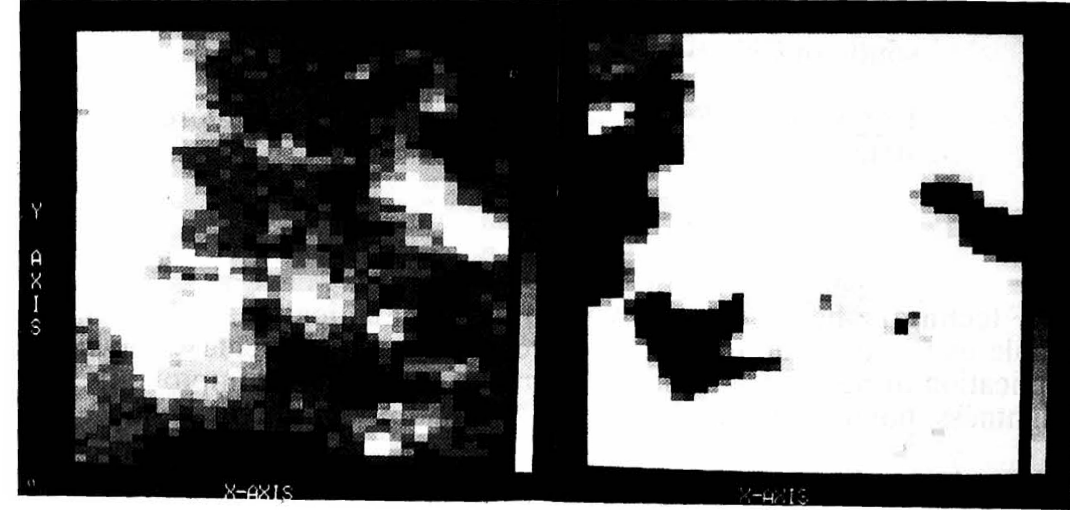

(c)

(d)

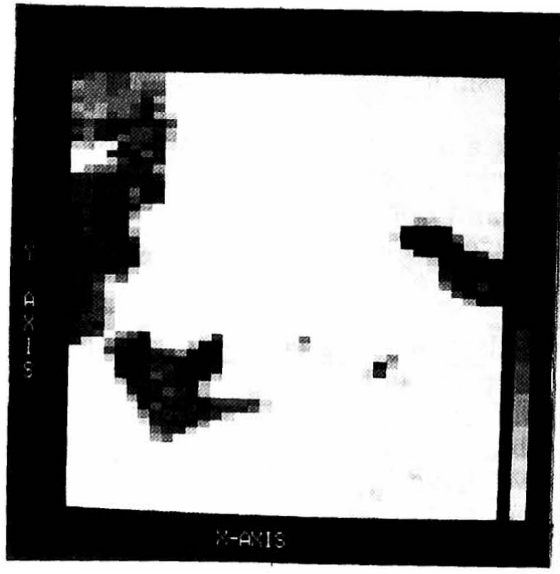

(e)

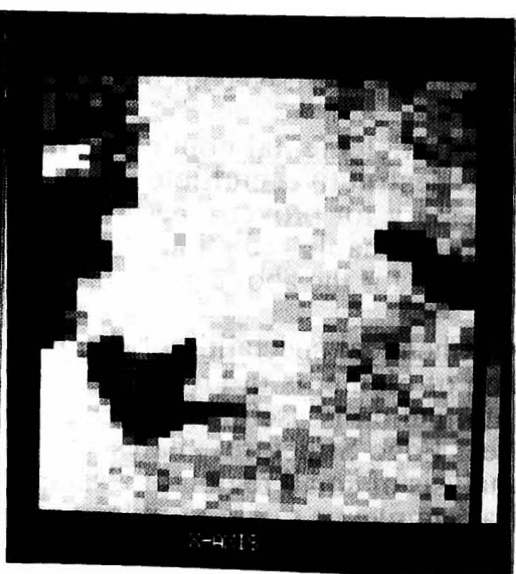

(1)
Fig. 2. Chemical imaging of ancient clay doll: (a) photograph of the sample, (b) analyzed part of the sample (c) Fe image, (d) $\mathrm{Pb}$ image, (e) Zn image and (f) Ca image. 
of the sample and are processed with a personal computer into two dimensional image on a graphic display. The compositional image is represented by 14 densities from black to white corresponding to the intensity of the fluorescence $\mathrm{X}$-rays of each element.

XANES spectra were measured by $\mathrm{X}$-ray fluorescence detection. Intensity of incident beam was monitored by an ionization chamber placed in front of the sample and that of the fluorescent $X$-rays was measured by the $\mathrm{Si}(\mathrm{Li})$ detector. XANES spectrum was obtained by normalizing the intensity of the fluorescent $\mathrm{X}$-rays with the incident intensity and by plotting the data against the $\mathrm{X}$-ray energy.

\section{Results and Discussion}

Figure 2 (a) shows a sample of the clay doll. Two dimensional chemical analysis of the doll was made for $\mathrm{Fe}, \mathrm{Pb}, \mathrm{Zn}$, and $\mathrm{Ca}$ on the area indicated by the frame in Fig. 2(b). The results are given in Figs. 2 (c), (d), (e) and (f), respectively. The distribution of $\mathrm{Pb}$ corresponds well with that of the red pigment on the body, hence the colorant is found to be red lead. The clay base contains a large amount of Fe, while white part only contains $\mathrm{Ca}$ and, if present, elements with atomic number smaller than 20 . Shells, i.e. calcium carbonate, may be used as the source of the white color. Both parts lack in $\mathrm{Pb}$. $\mathrm{A}$ large amount of $\mathrm{Pb}, \mathrm{Zn}$, and $\mathrm{Ca}$ is found in gray coating on the doll. In this way, this technique can be used to obtain knowledge of materials used in the decoration of archaeological objects.

Fe K-edge XANES spectra of Temmoku bowl and some reference compounds of iron were measured and are compared in Fig. 3. The spectra of reference compounds, (a) metallic iron ( $\mathrm{Fe}^{0}$ ), (b) olivine $\left(\mathrm{Mg}, \mathrm{Fe}^{2+}\right)_{2} \mathrm{SiO}_{4}$, and (c) hematite $\mathrm{Fe}^{3+} \mathrm{O}_{3}$ show chemical shift of their absorption edges depending on their oxidation states. The spectrum (d) in Fig. 2 was measured at the surrounding part of the oil spots and that of (e) on an oil spot of the Temmoku bowl. It is found that the absorption edge of the spectrum (d) is close to that of $\mathrm{Fe}^{2+}$ in olivine, while that of the oil spot (e) shifts to hematite (higher energy) side compared with the spectrum (d), hence iron in the oil spot is more oxidized compared with their surroundings. It is thought that the origin of the oil spots may be bubbles formed during the manufacturing process. Our observation could propose the following mechanism of the formation of the oil spots: i.e., thermal decomposition of the source material of the bowl produces gas and the oil spots were formed by bubbles of this oxidizing gas.

The smallest beam size obtained by the slits is c.a. $0.05 \times 0.05 \mathrm{~mm}^{2}$. This spatial resolution is small enough for archaeometric analysis, hence the present XRF technique can be used in the microprobe analyses of chemical state as well as chemical compositions of archaeological objects. This method is truly nondestructive and does not require any pretreatment of the sample. Besides, the SR facility provides spatial freedom, which allows the analysis of large artifacts such as sculptures, paintings, etc. It can be said that the Synchrotron Radiation is an ideal light source for XRF analysis of archaeological objects.

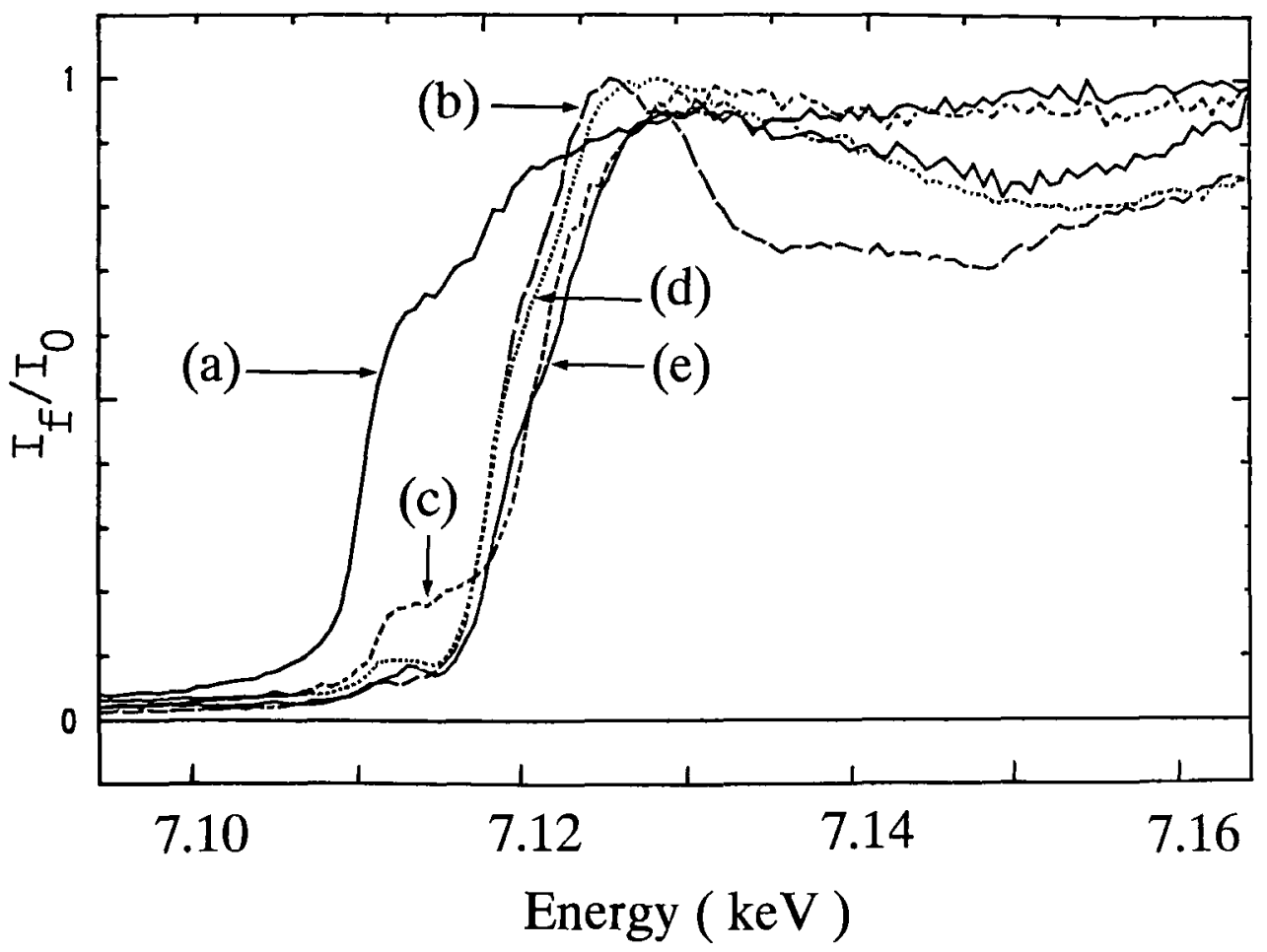

Fig. 3. Normalized Fe K-edge XANES spectra of reference compounds : (a)metallic iron ( $\mathrm{Fe}^{0}$ ), (b) olivine $\left(\mathrm{Mg}, \mathrm{Fe}^{2+}\right)_{2} \mathrm{SiO}_{4}$, (c) hematite $\mathrm{Fe}^{3+}{ }_{2} \mathrm{O}_{3}$, and those of (d) the glaze base and (e) the oil spot of the Temmoku bowl. 
The authors are grateful to Prof. Y. Ueno of Univ. of Tokyo for the loan of the clay doll. The authors also wish to thank Dr. A. Iida of PF, KEK for his kind advice during experiments at the Photon Factory. This work was partially supported by a Grant-in Aid for Scientific Research from the Ministry of Education.

\section{REFERENCES}

1. I. Nakai, A. Mochizuki, A. Iida, I. Taguchi and K. Yamasaki, Bull. Natl. Mus. of Jap. History (1991) in press.

2. F. Koyama and K. Yamasaki, Sci. Papers on Japanese Antiques and Art Crafts, No.6, 19 (1953). 